\title{
Reflexive VR Storytelling Design Beyond Immersion: Facilitating Self-Reflection on Death and Loneliness
}

\author{
Sojung Bahng \\ SensiLab, Faculty of \\ Information Technology \\ Monash University \\ Melbourne, Australia \\ sojung.bahng@monash.edu
}

\author{
Ryan M. Kelly \\ School of Computing and \\ Information Systems \\ The University of Melbourne \\ Melbourne, Australia \\ ryan.kelly@unimelb.edu.au
}

\author{
Jon McCormack \\ SensiLab, Faculty of \\ Information Technology \\ Monash University \\ Melbourne, Australia \\ jon.mccormack@monash.edu
}
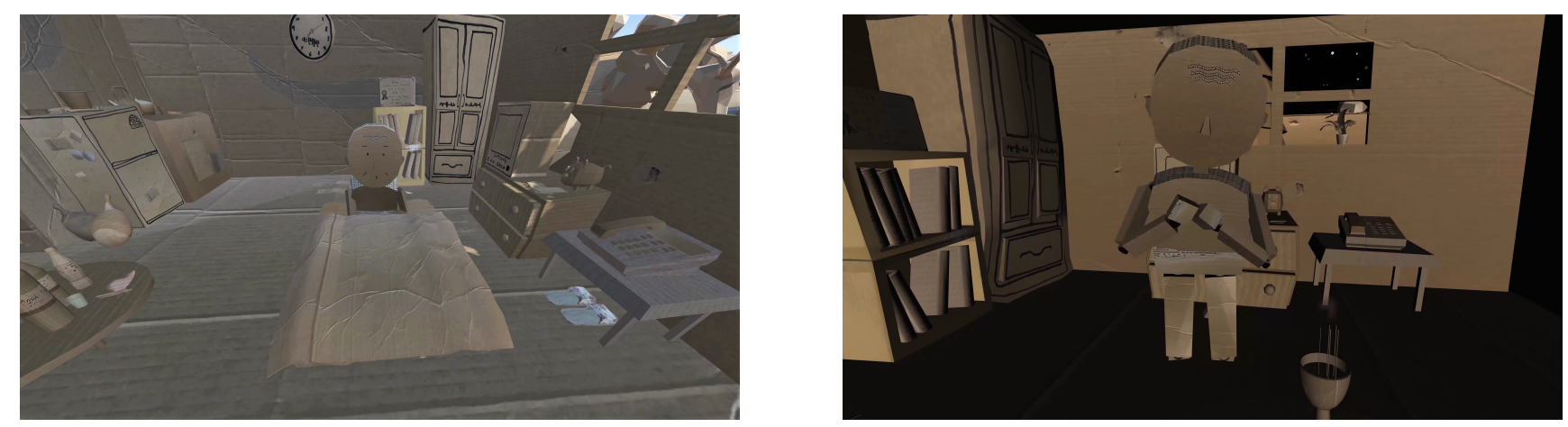

Figure 1: Scenes from Anonymous, an interactive cinematic virtual reality story about death and loneliness.

\begin{abstract}
This research examines the reflexive dimensions of cinematic virtual reality (CVR) storytelling. We created Anonymous, an interactive CVR piece that employs a reflexive storytelling method. This method is based on distancing effects and is used to elicit audience awareness and self-reflection about loneliness and death. To understand the audience's experiences, we conducted in-depth interviews to study which design factors and elements prompted reflexive thoughts and feelings. Our findings highlight how the audience experience was impacted by four reflexive dimensions: abstract and minimal aesthetics, everyday materials and textures, the restriction of control, and multiple, disembodied points of view. We use our findings to discuss how these dimensions can inform the design of VR storytelling experiences that provoke self and social reflection.
\end{abstract}

\section{Author Keywords}

Alienation; Cinematic VR; Distancing Effect; Estrangement; Immersive Storytelling; Reflexivity; Virtual Reality.

\section{CHI '20, April 25-30, 2020, Honolulu, HI, USA.}

(C) 2020 Copyright held by the owner/author(s). Publication rights licensed to ACM. This is the author's version of the work. It is posted here for your personal use. Not for redistribution.

The definitive Version of Record was published in Proceedings of the SIGCHI Conference on Human Factors in Computing Systems (CHI 2020), April 25-30, 2020, Honolulu, HI, USA

https://dx.doi.org/10.1145/3313831.3376582

\section{CCS Concepts}

-Human-centered computing $\rightarrow$ Virtual reality; Empirical studies in HCI;

\section{INTRODUCTION}

The virtual reality (VR) industry has grown rapidly, and many filmmakers and artists have begun to use VR as a creative storytelling medium $[33,41]$. However, the reflexive dimensions of VR storytelling are not well understood. These dimensions encapsulate how particular methods of storytelling elicit self awareness and reflection around key topics within the story.

VR has often been called an empathy machine due to the interactive and immersive experience it can create, alongside the ability to create the embodiment and presence of another person through a first-person perspective [21,38]. However, storytelling design for immersive engagement has potential pitfalls, including uncritical acceptance and passive identification. In art, distancing effects (also known as estrangement or alienation effects) were developed in many art forms to break simple immersion and identification and to provoke self-awareness, social awareness, and reflection [9, 29,56].

Research on VR storytelling predominantly considers the reconciliation between interactivity and immersion to intensify audience engagement in virtual environments [48]. Because the reflexive modes of distancing effects are contradictory to immersive technology, explorations of reflexivity have the potential to disrupt the fundamental immersive nature of VR. Since there is a fundamental tension between immersion and 
distance, it is challenging to apply distancing effects to VR. Nevertheless, we can develop reflexive storytelling by using technical restrictions and media constraints inherent to VR, and which do not necessarily break immersion [3].

Exploring storytelling elements for reflection in HCI is highly challenging because the audience's reflections about stories are subjective and complex. Furthermore, research on VR storytelling is still new, and reflexive dimensions are difficult to study with the current lack of established VR storytelling vocabulary (which is still growing and changing). Considering these limitations and the lack of traditions, we see a need to explore reflexive VR storytelling in practice.

In this paper, we study an interactive cinematic VR (CVR) piece titled Anonymous [4]. The storytelling was designed to make audiences reflect on loneliness and death. Anonymous addresses the issue of the "no-relationship society" in South Korea, where people are increasingly living and dying alone $[23,55]$. However, loneliness and social isolation among elderly people are worldwide problems, and so provoking reflection and awareness of this topic is relevant more broadly. Furthermore, all human beings die, and each of us must deal with death in our own way, meaning that it is necessary to reflect on the issue of death at some point. HCI researchers have recognised the need to address themes of death and mortality [31]. Previous work in the area of thanatosensitive design has explored how bespoke physical artefacts [58], photography [19], and the participatory design of personally meaningful objects [39] can provoke reflections on death, grief and bereavement $[30,32,57]$. This literature has shown that technology can prompt reflection for specific groups of people, including the elderly or bereaved family members, but it did not focus on reflections about death and loneliness through the use of storytelling and VR.

To address these gaps, we conducted a qualitative study to understand the audience experience of Anonymous. This allowed us to discover which design elements and distancing effects elicited reflexive thoughts and feelings. Based on a thematic analysis of the interview data, we contribute an understanding of how four reflexive dimensions can support VR storytelling: (i) abstract and minimal aesthetics, (ii) everyday materials and textures, (iii) the restriction of audience control and freedom, and, (iv) multiple, disembodied points of view. Based on our findings, we discuss the reflexive dimensions of VR storytelling and present potential design opportunities for eliciting self-reflection about social issues related to isolation, alienation and mortality. This work provides a rich understanding of reflexive VR storytelling in practice and brings those considerations to design implications.

\section{RELATED WORK}

Our practical investigation draws on prior research related to storytelling in cinematic VR and the use of distancing effects in digital media.

\section{Storytelling in Cinematic Virtual Reality}

VR storytelling design is a multidisciplinary practice that requires many technical decisions and considerations related to audience engagement. Due to its intertwined and complex nature, $\mathrm{HCI}$ researchers have correspondingly begun to consider the experiential qualities of storytelling in VR. Despite the increasing attention, narrative and story have mainly been considered or examined as sub-elements for inducing emotional engagement or sense of presence $[18,52]$. Other work has studied a variety of user experiences with VR, including the perception of sudden exit from VR [25], the role of VR in exposure therapy [15] and how VR environments should shape pro-social interaction [36]. One recent study systematically analysed the content of virtual-reality nonfiction experiences (VRNF), including story and technical experimentation [5]. However, less attention has been given to the audience experience of stories delivered in VR.

Research on immersive storytelling has been mainly focused in the digital storytelling and cinema studies disciplines. The meaning of immersive storytelling has not been fully agreed upon, but there is agreement that immersive storytelling methods can make audience members feel more emotionally involved and engaged in a story or narrative [40,54]. A key element of immersive storytelling for VR is eliciting a sense of presence and embodiment from users or audience members within the virtual environment $[10,35]$.

Storytelling is broadly understood as a fundamental way of expressing ourselves and our world to others by organizing different types of information [34]. The grammar and syntax of CVR storytelling is still being developed. Marie-Laure Ryan [48] claimed that VR can bring exploratory interactivity to traditional, passive film narratives since the audience can view the environment from multiple angles. Therefore, the audience could actively engage in the virtual story world. She also argued that interactivity in VR should be based on body gestures so as not to destroy illusion in immersive environments.

CVR has been used as an artistic and creative tool to simulate the experience of solitary confinement and isolation [5,28]. A $360^{\circ}$ video work entitled After Solitary, by Cassandra Herrman and Lauren Mucciolo (2017), shares the story of one individual who stayed in prison for a long time. Another $360^{\circ}$ work, Remain at Home, by Gero A. E. Egger (2017), embodies the viewer as an elderly person who remained at home during the war. These two works use the restricted movement of a $360^{\circ}$ camera to simulate the sensation of confinement. The viewer is able to look around the scene in any direction, but cannot move from their position within the environment.

There is also a 3D-rendered interactive CVR work, titled $6 \times 9$, by Francesca Panetta (2016), that simulates the experience of being in a prison cell. Using gaze-based interactions, it is possible to trigger events that give the viewer a sense of how it feels to be imprisoned. Similarly, Unrest, by Jennifer Brea and Amaury La Burthe (2017), is a 3D CVR work that shares the perspective and sensations of a woman suffering from chronic fatigue syndrome. The interaction is used primarily to 'draw' neural brain connections, in order to convey the unknown aetiology of chronic fatigue syndrome. All these works are designed to simulate the sensations of loneliness and solitude, but there was no reported exploration of the reflexive dimensions of storytelling within them. 


\section{Distancing Effects in Digital Media}

Although CVR storytelling is predominantly focused on immersion, many digital media art explorations of reflexive storytelling have applied distancing effects. In art and cinema, reflexivity usually has two meanings. The first is revealing a creator, creative process or structure to demystify these elements, and the second is to make audience members return to themselves rather than simply engaging in the immersive illusion $[44,46]$. These two elements are not separate or mutually exclusive.

In theatre and cinema, reflexive storytelling and aesthetic techniques have been developed based on Brechtian distancing effects. Brecht criticized the traditional Aristotelian narrative that forces audiences to identify with characters and engage in illusive dramatic immersion [9]. Aristotelian narrative form is based on identification with the protagonist, which typically leads audience members to an emotional release and catharsis [2]. Brecht identified the dangers of Aristotelian narratives that block critical thinking and awareness, and hence can be used to control audiences for specific political or ideological purposes.

Brecht used diverse reflexive and distancing techniques to break the illusion and fantasy of drama, provoking audience self-awareness and critical thinking [7, 9, 14]. For instance, his actors did not identify themselves with their characters and asked the audience questions to make them aware that the performance was not real. He often used complex, inconsistent narrative structures to make the audience 'fill in the gaps'. Avant-garde experimental cinema adopted Brechtian techniques in various ways, such as through the use of fragmented collage effects, inconsistent narrative structures, and dislocated performative styles $[44,56]$. Jean-Luc Godard is a representative film director who used distancing effects deliberately. For example, the loosening of continuity in dramatic structure, interruptions and reminders of the medium, and simple or distorted visuals and sounds are used to interrupt the identification process and provoke audience members' direct intellectual involvement [56].

In digital media (e.g. interactive films, database films and video games), distancing effects and reflexive dimensions have been explored in numerous ways. There has been research on interactive films and database cinema that apply several distancing effects from Brechtian film theory, such as discontinuous narrative structures, dis-unified aesthetic forms, and hypertextual choices [12,29]. There have also been attempts in video games to break the player's engagement by creating sudden changes in visuals or interfaces $[13,16]$. Dunne said that (psychological) immersion and alienation can work together to push and pull audiences into and out of the game [13]. Frasca proposed a new video game design based on the main characteristics of Boal's Theatre of the Oppressed techniques, which foster spectators' critical thinking and political participation in theater [16]. In that project, players are encouraged to change the code or system to modify the given rules of the game.

In her classic text Computers as Theatre, Brenda Laurel claimed that HCI mirrors the art of improvisational theatre because it allows agents to interact freely with the given en- vironment [27]. In this way, CVR can be metaphorically considered as improvisational theatre in the HCI context, because the audience, as an agent, can interact with characters or the environment in a virtual setting. Therefore, distancing effects from the theatre tradition can be used as reflexive dimensions for eliciting self-reflection in CVR.

Although there is a lack of research on reflexive dimensions in CVR, there have been many attempts to explore reflection and reflexivity in the HCI literature. Prior explorations of reflective design [50] and slow technology [20,43] demonstrate the potential for interactive systems to encourage provocative reflection on everyday matters of concern. Many reflective design researchers embrace ongoing self-evaluation and the dedication of critical attention to one's actions during the design process $[26,49,50]$. However, these do not necessarily relate to VR or storytelling design. Some researchers have explored estrangement and distancing effects in HCI, but they have mainly focused on designing artefacts or performances $[42,60]$.

\section{ANONYMOUS: DESIGN AND APPROACH}

Anonymous is an interactive CVR piece about death and loneliness in South Korea. The main theme of Anonymous is the notion of the "no-relationship society", which is a concept that originated in Japan. Known in Japanese as muen-shakai, it refers to the phenomenon of older people living and dying alone, and whose bodies are often not found for long periods of time after their death [55]. Many old people live alone, with neither mental nor physical support, and face the prospect of a lonely death. At least 4.3 million older adults are thought to live alone in Japan [17], and this issue has become pertinent in other countries, including South Korea [23].

Social isolation is intertwined with many complex issues including ageing, economic crises, the welfare system, globalization, and deconstruction of the traditional family unit $[1,22,23]$. These issues are not solely a problem for Asian societies, however. Globally, an increasing number of people are choosing to live alone [24], and loneliness has been characterised as a growing problem in many countries [11], especially among older people [51]. Any modernized and segregated society has the potential to experience issues related to isolation, disconnection, and loneliness. It is therefore crucial to confront the issue of the no-relationship society, reflect on its causes, and on the issues of death and loneliness in contemporary culture. Problematically, mass media has tended to deal with these kinds of topics as 'stimulating' experiences that only happen to 'certain types of poor people' [61]. However, we all age and die, and everyone has a risk of becoming isolated in life, so reflecting on these issues provides an opening to finding better solutions.

VR can be a good tool to simulate the experience of solitary confinement and loneliness, thereby provoking embodied identification with a person who is in such a situation [28]. However, if we identify with a certain tragic character, without awareness of our reflection in the virtual situation, the character may ultimately be nothing more than object onto which we project our emotions and feelings of catharsis, and then a sense of relief from our tragic feelings when we come back to real 


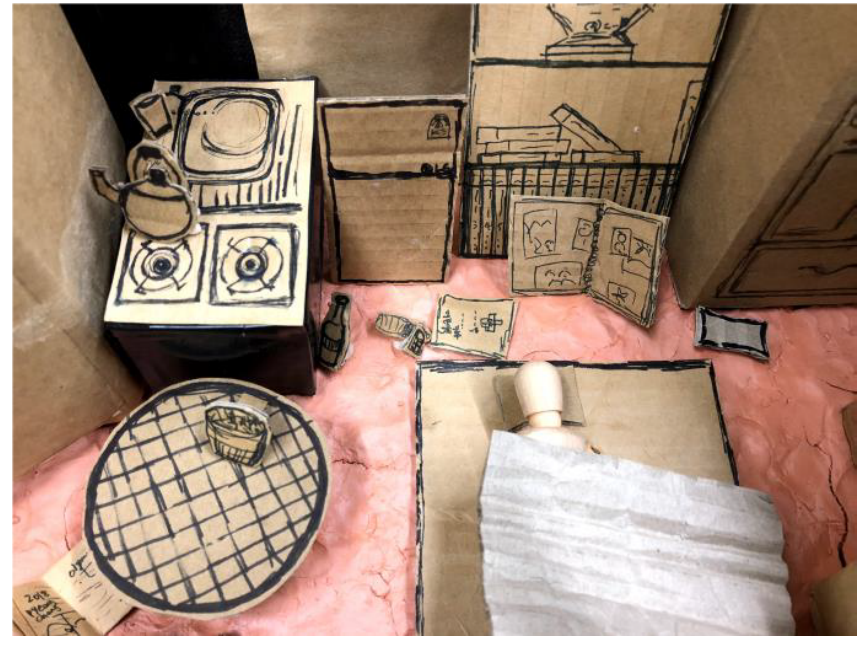

Figure 2: Initial diorama of Anonymous using physical cardboard.

life. This outcome may exemplify the dangers of Aristotelian narrative that Brecht has previously criticized [44].

Given the significance of these issues, we aimed to use CVR to connect the audience to loneliness and death, while eliciting reflection on both of these topics.

\section{Immersion, Interactivity and Narrative}

The method of designing VR storytelling aligns with the technical elements of VR. In such contexts, we examine three primary factors: immersion, interactivity, and narrative.

Regarding immersion, we use the interpretations of immersion by Slater and Wilbur [53]. They defined VR immersion as a quantifiable property of a technology or system and described immersion as being inclusive, extensive, surrounding, and vivid. The inclusive property is the degree to which physical reality is shut out, and the extensive property is the range of sensory modalities accommodated by the technology. The surrounding property is the degree to which the display is panoramic, and the vivid property is the resolution or quality of the display. Matching is also a significant factor of immersion, which refers to the correspondence between the participant's movements and the information generated by the system.

Ryan $[47,48]$ claimed that the interactivity of VR gives the user power to modify the environment. However, Vosmeer and Schouten concluded that interactivity in VR is simply looking around and exploring a sequence within a $360^{\circ}$ movie [59]. We define interactivity as the degree to which an audience can navigate in, and affect, a virtual environment.

Narrative can be conceived as a broad and ambiguous word, but it is generally understood as a form of representation structure and model. Ryan [47] categorized narrative into three types: sequential narrative, causal narrative, and dramatic narrative (the Aristotelian concept of plot). From these concepts, we identify narrative as the structural form of storytelling.

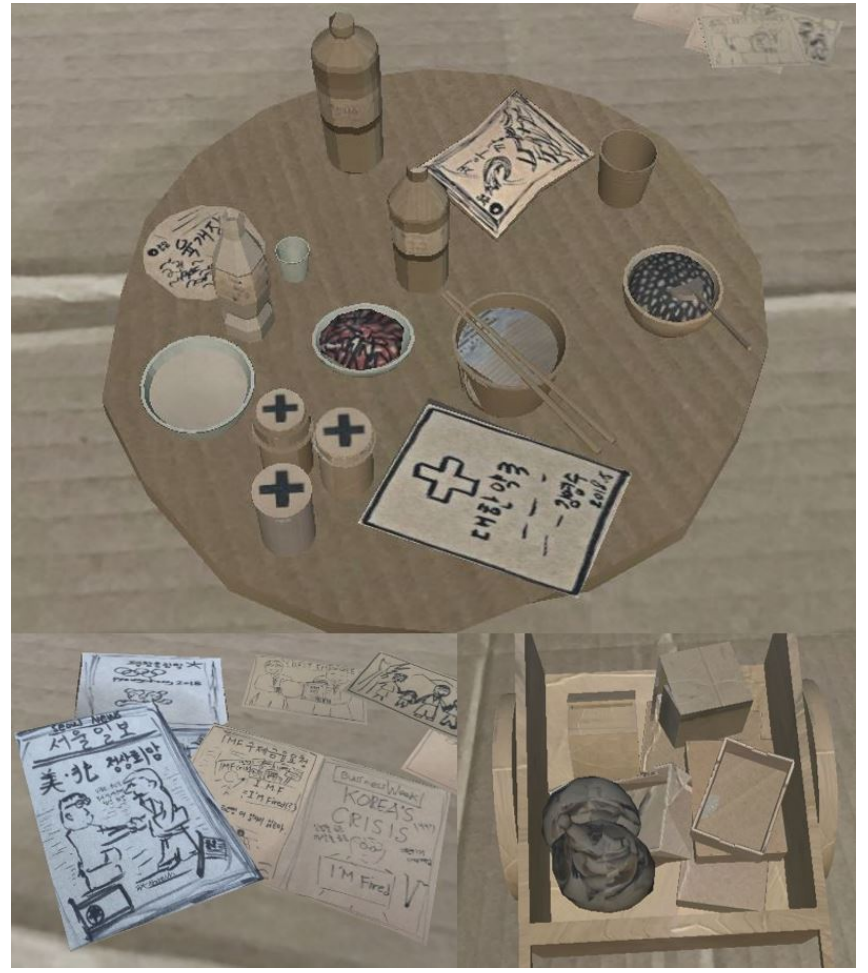

Figure 3: Objects in Anonymous.

For effective reflexive storytelling in this work, we apply the factors of immersion, interactivity, and narrative as follows:

Immersion: highly immersive real-time 3-D rendered graphics and Oculus Go are used for this work, so its vividness was considered quite strong - although matching was relatively limited because the audience was not allowed to physically move around in VR.

Interactivity: gaze-based interactions are used to trigger events in Anonymous, allowing the audience to assume the perspective of different objects in the narrative. The user cannot move freely around the virtual scene because their perspective is anchored to fixed points, but they can move their head to look around the environment.

Narrative: the story concerns an old man living alone while remembering his past life and his deceased wife. This choice was inspired by the first author's experience of volunteering in a Senior Welfare Centre in South Korea. The narrative style is based on a silent animated movie.

Anonymous was designed to be experienced in a seated position, because we believed that non-navigability can be used as a tool to simulate solitude and loneliness. Triggering events based on gaze allowed us to compel the audiences' engagement with the linear narrative, instead of permitting them to choose which events are worthy of attention. However, we used the interaction to simulate the focus, observation and sense of looking at particular objects within the virtual environment. The narrative style was inspired by abstract animated silent films, to elicit audience engagement in the story, but 


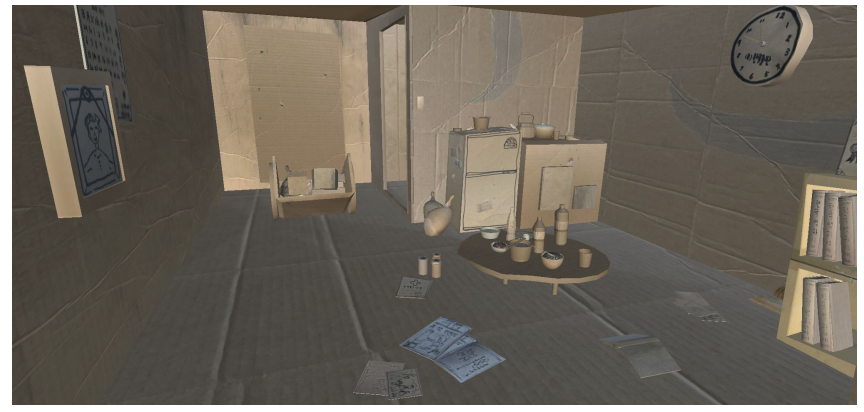

Figure 4: The virtual environment of Anonymous.

in ways that were not limited by language or to any specific ethnicity or gender.

Based on these considerations, we designed our process of storytelling to make audiences assume the role of a deceased person who can watch a solitary family member by inhabiting objects in the virtual environment. We wanted to use the disembodiment feature of VR as a tool to create different kinds of experiences, such as the experience of becoming a dead person and inhabiting objects, which may make audiences engage in the virtual world from an unfamiliar distance.

\section{Story}

The story of Anonymous proceeds as follows:

The audience enters the virtual world, which is made entirely of cardboard. The main character is a widower, who prepares an annual ceremony to memorialize his dead wife. The audience assumes the perspective or position of the dead wife's portrait, which assigns them the role of a dead wife. From the position of the dead wife's portrait, the audience observes the character's solitary daily life which includes such activities as waking up, going to the toilet, and eating, but they cannot interact with him. A butterfly in the room guides the audience's gaze to specific objects; by gazing at the object they can 'become' that object. The camera perspective shifts to a different position to show the environment from the object's perspective, opening up opportunities for conveying specific sub-narratives within the work.

Anonymous has different objects for the audience to inhabit. For example, from within the TV, the audience sees the news, including recent events like the summit between North Korea and the US. They can also become the butterfly, slowly moving around the room and watching the widower's life from above, while he is remembering his past experiences. The audience inhabits a telephone, hearing the voice of an absent daughter, who explains why she cannot visit the widower today. After the audience transforms into a light, again looking down on the widower's life from above, they witness the ritual for his dead wife. At the end of the story, the audience is led out of the home and up into the sky, becoming a star.

\section{Design Process}

Developing Anonymous required multiple design activities. The story itself was inspired by the first author's experience of volunteering to help with housework (such as cooking and

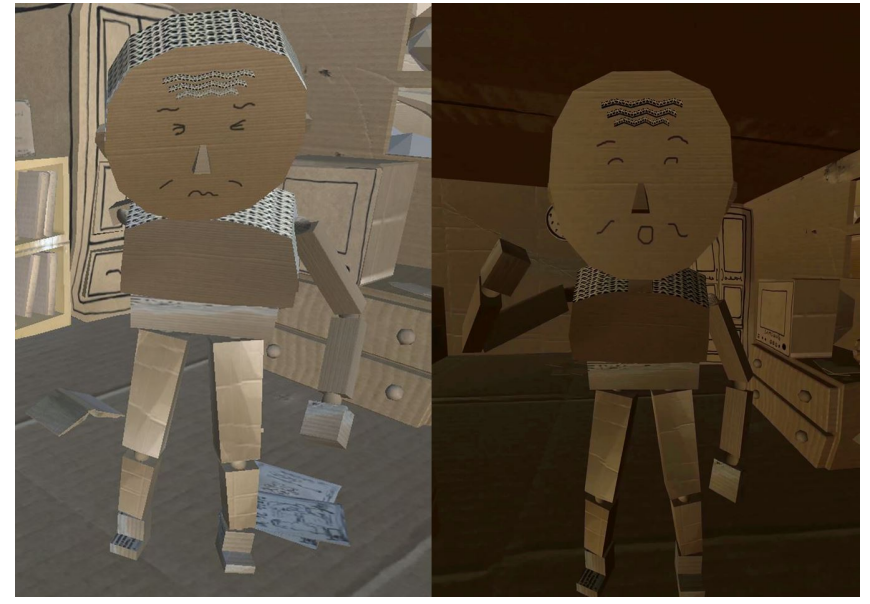

Figure 5: The widower character from Anonymous.

cleaning) for an old man who lives alone in South Korea [4]. This experience lasted two and a half weeks, and informed the story by orienting our design sensibility to the lived experience of a lonely older adult, as opposed to systematic collection and analysis of data. Following reflexive understanding of the personal experience, the character and environment were poetically (rather than realistically) reconstructed. Although the subject has not seen the work, we designed it in a such a way that he would not be identifiable through the story.

We first created a physical, small-scale model using cardboard for specifying the aesthetics, structure and narrative while exploring real cardboard textures. Figure 2 displays the diorama. We filmed the model with a $360^{\circ}$ camera, enabling us to conceptualize and refine the design in the pre-production stage of creating the virtual environment. We translated the cardboard texture to the 3D environment to symbolize fragility, familiarity and finitude.

We aimed to defamiliarize the familiar objects in the poetic reconstruction. The childish drawing style is related to representations of the unconscious self and inner child that can be more connected to fundamental feelings of loneliness and the fear of separation. We tried to vitalize objects as much as possible, and the objects represent and embrace the history of South Korean society and everyday life in social contexts. We tried to articulate the objects through 3D modeling and kept adding more details to refine the overall aesthetic. Examples of these objects are shown in Figure 3.

The structure of the main character started from the impersonal, fragile and unnatural wooden mannequin. We developed the character by adding more cardboard textures and changing body proportions. We also created many different facial textures to express his emotions and used motion capture technology to create the character's animated motion, such as walking, reading, eating, and standing. The final character is reminiscent of the elderly gentleman from the aforementioned voluntary work. One difference is that the virtual character in the story of Anonymous was a book salesman until he got fired during the IMF crisis. He now makes money by collect- 


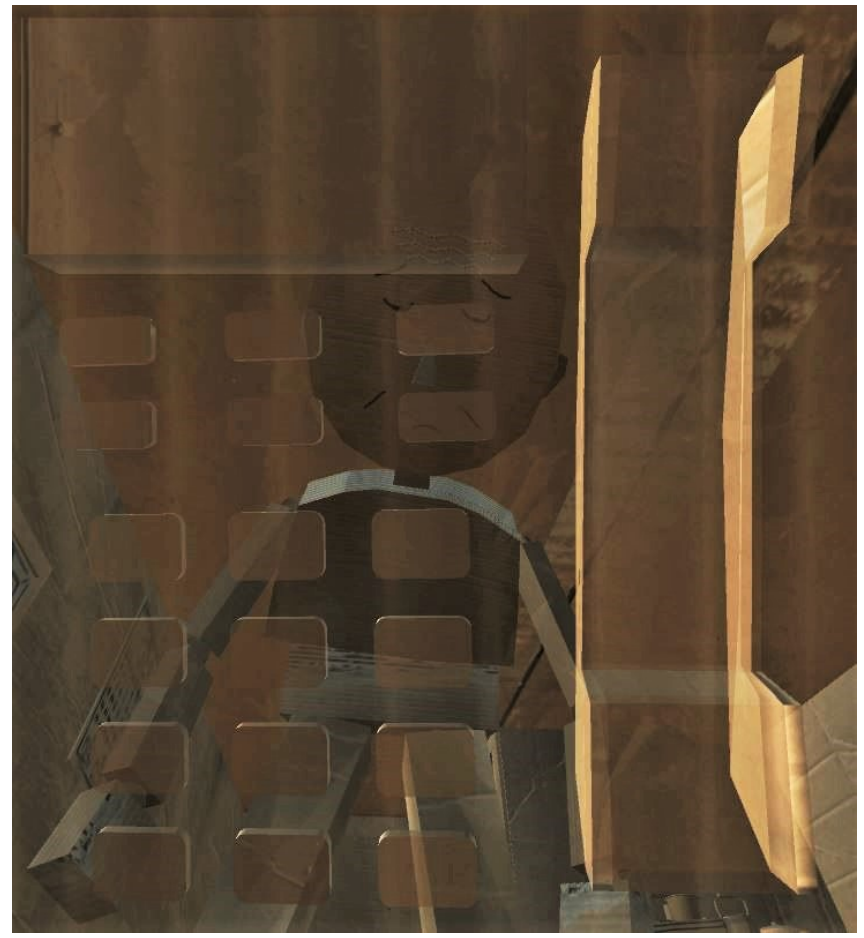

Figure 6: Screenshot of the viewer inhabiting an object within Anonymous. In this image, the viewer's perspective is shown from inside the main character's telephone. The foreground of the image shows the telephone's number pad and handset, and the main character appears in the background.

ing waste papers (which is how many elderly Korean people make money) whereas the real person was an unemployed businessman.

For the sound, we used a 3D spatial audio recorder to collect ambient environmental sounds while in South Korea. We recorded abstract sound effects and ambiences using cardboard textures and found materials. We recorded the character's voice such that it was humanlike, but with muffled and unintelligible voice sounds. The intention was to make the audience imagine or guess his feelings from the intonations rather than from literal dialogue or words. This also makes it possible for the piece to be interpreted by a wide range of people, as opposed to only Korean native speakers.

After finalizing the 3D environment and the character, we combined them with the animation data in the Unity game engine to create a story and apply gaze interactions. We used a commercial Oculus Go headset to deliver the piece to the audience.

To simulate the experience of becoming objects, we had to make people feel that they were inhabiting objects. Visualizing this concept using VR technology was very challenging. When objects were too close to the camera, perceptions were distorted and the proximity of the front clipping plane caused the mesh to disappear. Further, when camera perspectives diverge from human perception, such as being upside down or inclined, people may become sick or confused. Thus, camera

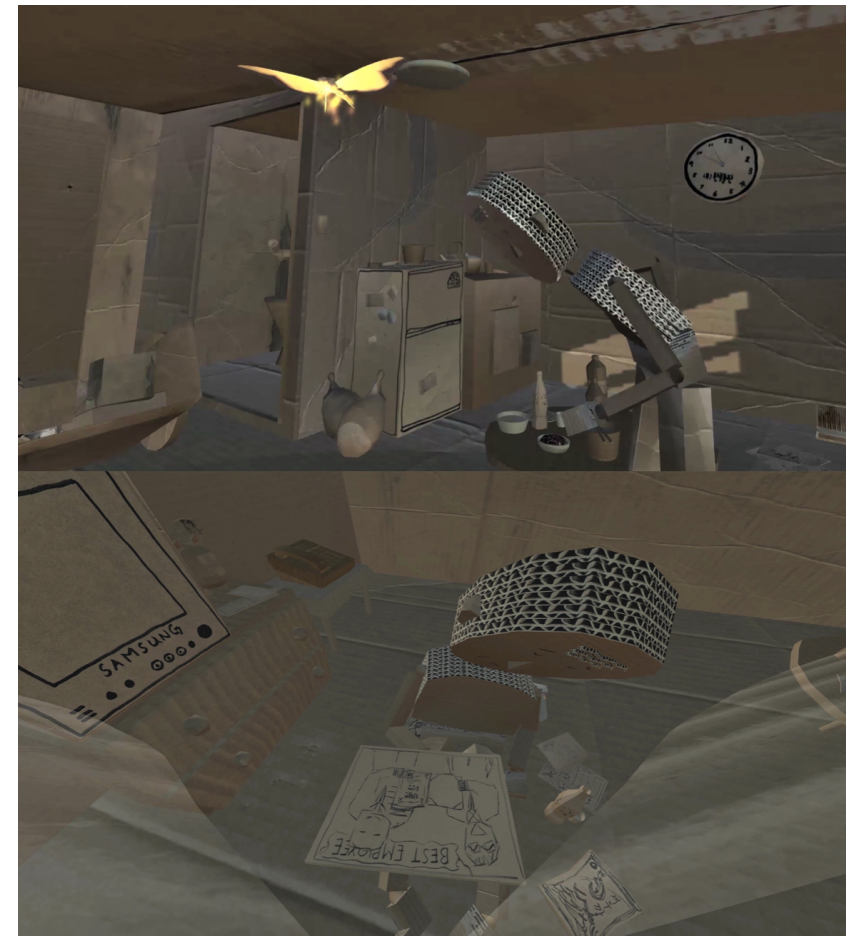

Figure 7: Screenshots of becoming the butterfly. The upper half of the image shows the viewer's perspective when gazing at the butterfly. The lower half shows the viewer's perspective when they are embodied as the butterfly.

movement required careful adjustment to prevent motion sickness. We kept changing and modifying these designs through iterative informal feedback from colleagues and VR experts. Striking a balance between creative intentions and technical limitations was difficult, but the process of exploring VR technologies and refining the realistic grammar of VR storytelling was informative in terms of understanding the potential for VR to support reflexive storytelling.

\section{METHOD}

To explore the audience's experiences of Anonymous, we invited 23 participants ( 10 females and 13 males) to experience the work and complete in-depth interviews. Participants' ages ranged from 25 to $70(\mathrm{M}=38$ years). Ten participants were South Korean nationals and 13 participants were from outside Korea (2 from Malaysia, 1 from Italy, 1 from Netherlands, 1 from Brazil, 1 from Chile, 1 from the USA, and 6 from Australia). The work is based on South Korean society, so we deliberately recruited people from South Korea to explore differences between their perceptions and those of non-Korean participants. We sought to determine whether certain design factors or storytelling elements affected participants differently based on their nationalities and socio-cultural backgrounds.

All participants were self-selecting and were recruited as a convenience sample using personal contacts. Ten of the participants had not used VR before. The participants received no financial compensation for their involvement in the study. 


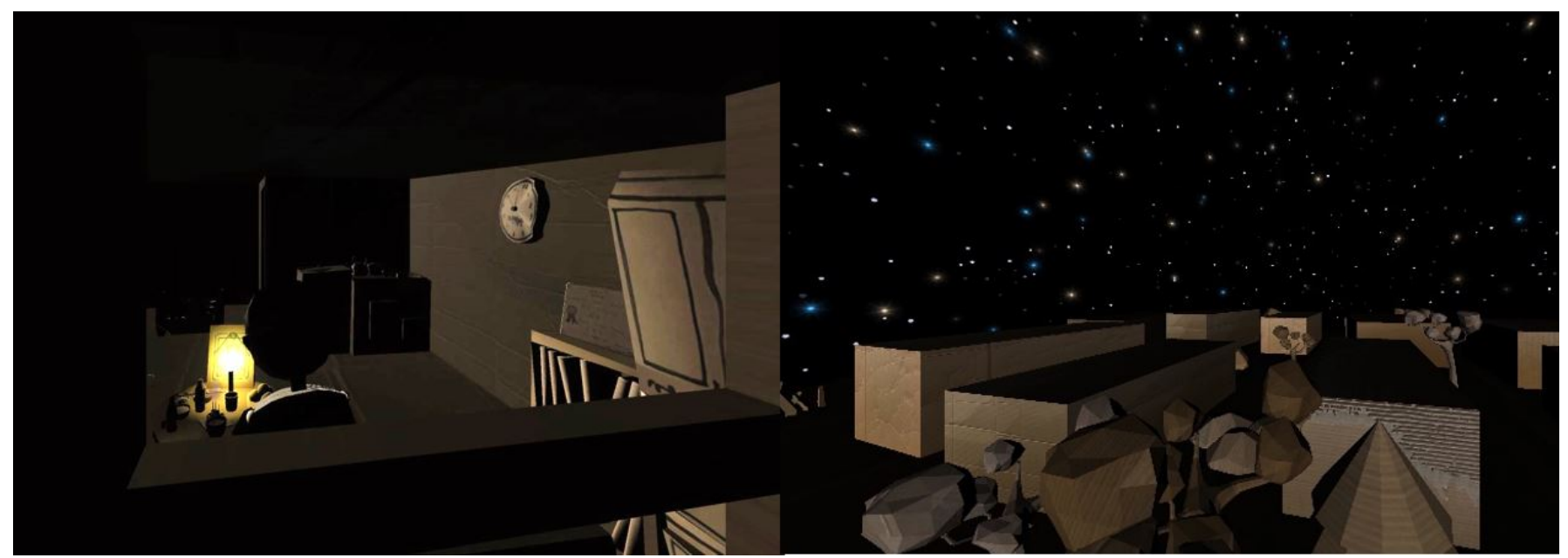

Figure 8: Screenshots of the final scene in Anonymous.

We set up a quiet and private environment for sharing Anonymous, inviting participants to a private studio or to a meeting room to view the piece. Each participant was given an Oculus Go headset and was able to watch Anonymous in a seated position. After viewing the piece, we conducted an in-depth interview to probe the audience experience. We used a semi-structured interview process. We started with questions regarding their thoughts and feelings about the work. Example questions included "what are your first thoughts and feelings about this work?", "did this remind you of anything?" and "what did you think about the main character?". We continued the conversation based on their responses and how they reflected on their own life experiences, asking more about specific design elements ("how did you feel when you embodied the perception of objects?"). The interviews lasted 45 minutes on average (30-60 minutes). All interviews were one-to-one between participants and the first author, and informed consent was collected. All interviews were audio recorded.

\section{Data Analysis}

The first author transcribed all the interviews, including translation of the Korean participants' interviews into English. We analysed the data using an inductive thematic analysis following Braun and Clarke's six phase approach [8]. Having transcribed, read and re-read the data (Phase 1), we conducted open coding (Phase 2) in which the first author labelled printed transcripts to create codes and developed these codes into themes (Phase 3). As an example, the "limited interaction" and "impossibility of movement" codes were formed into the theme of "Restriction of Control". Phases 4 through 6 involved refining the themes through thematic mapping, consolidation of codes and discussion among the authors. This process highlighted four recurrent topics: abstract and minimal aesthetics, everyday materials and textures, the restriction of control, and the various disembodied points of view. These topics form the basis of our findings section below.

\section{FINDINGS}

Our participants expressed a range of reactions to the content of Anonymous. We first tried to separate these responses in terms of differences between South Koreans and non-Koreans, but we did not find any major differences based on nationality or sociocultural context. Almost every participant said that this work dealt with fundamental issues using general aesthetics, and none found the work unfamiliar and awkward, even though it played on Eastern rituals and included objects that symbolize specific parts of South Korean society.

One minor difference was that South Koreans read more about the sociocultural background of the main character. Along with participants from other Asian countries, the piece made them talk more about spirituality related to Buddhism and concepts from Taoism: "I thought of the problem of reincarnation when I was a butterfly" (P6). This suggests that the reflexive design elements of Anonymous made people find their own interpretations, in a way that is not limited to the particular context but allows them to project their personal and sociocultural experiences. In terms of age differences, 8 of the 23 participants were aged 38 or above. However, we did not observe distinctive differences between generations, suggesting that the piece was more successful in drawing out individual rather than age-related differences.

\section{The Use of Abstract and Minimal Aesthetics}

We found that using abstract and minimal aesthetics elicited projection with emotional distance. Because the main character was made of cardboard with an abstract hand-drawn expression, 20 participants mentioned they could easily project their feelings onto him with psychological distance. General and abstract figures made participants think more about their feelings toward the man:

"Since it is all made of cardboard, I didn't need to focus on many trivial details. I could only see the essence of his expression and action." (P7)

"We can project anyone to him, so he reminded me of the general human being rather than a specific person. Also, because it doesn't look too real, I felt a bit more comfortable to see the old man's solitary life." (P18) 
As the participant described above, general and abstract figures made the participants think more about their own feelings towards the character with some psychological distance. Although the character was created using cardboard material with minimal hand-drawn facial expressions, the participants could still feel certain emotions toward him as a human being through associations with gesture, contexts, figures or sound.

However, there are interpretative gaps that the audience had to fill in because he did not look too real. In other words, they were able to easily project a person or being associated with their own experiences or memories. For example, participants projected many different people from their real lives, such as their parents, spouses, themselves or people in general:

"He reminds me of my dad that passed away, but my dad didn't get too old, so it was a very fast moment. He reminds me of being old, and there is my husband. Because I already became part of that woman, I felt he is my husband." (P17)

Twelve of the participants said that the character reminded them of their family members, but their descriptions about the character's personality and situation varied. Participant 3 described his father, who was left behind when his family members died, being overwhelmed by his loneliness and being unable to let them go. Participant 6 talked about his parents living far away and them having some health issues. Participant 2 described a recurring dream she had where she meets her father who had passed away. Participant 12 mentioned that she was reminded of her husband when they were in a long-distance relationship, and that she found the character cute and adorable because he was trying hard to sustain a daily routine by waking up early, preparing meals for himself and taking medicine.

The remaining participants said that they saw the widower as a general human being who was old and lonely rather than a specific person, but the way they described their feelings about him was diverse, using terms such as sad, pitiful, adorable, sorry, attached or disinterested. These different responses represent how the work elicited the participants' self-reflections, each of which carried its own interpretation, rather than immersing them into the story in a specific way.

Furthermore, 6 participants said that the minimal dialogue and slow pacing of the story helped them to contemplate the character and themselves:

"Having the character, sort of making grunting sounds rather than doing any talking. I think it makes a sort of transcending language. You don't need to understand the language to understand what's happening." (P13)

The abstract and minimal aesthetics gave the audience a general sense about human beings without being limited to race, ethnicity, and appearance. Because it was not too realistic, they were able to maintain an emotional distance or boundary to project their own feelings and thoughts-which is reflexive.

"I think the animatic and abstract aesthetics with the cardboard created more empathy for the main character. It felt weak and fragile. If it were too realistic, I would have felt like a film objectifies the poor person and situation.” (P8)

\section{The Use of Everyday Materials and Textures}

We found that applying everyday materials and textures, like cardboard, makes familiar things seem strange. Ten participants described that using everyday cardboard strangely made them more physically engaged, and it led them to consider the similarity between cardboard and life, which is vulnerable, fragile, and recyclable:

"I guess because it is kind of mundane, and everyday materials... it creates the sense of artificiality, but because it is such an everyday material, so it kind of sense what it is, what it feels like, so it made more physical." (P23)

"The texture of the cardboard clearly showed his present and future. The abandoned fragile papers, there is no future, but he still lives so hard. He is fragile but still alive." (P18)

Cardboard is a mundane material, so we physically feel and sense the texture and materiality. Nevertheless, it is impossible to live in a cardboard world. Those tensions between familiar sensations and impossible strange situations create paradoxical feelings that made participants see their life in poetic and metaphorical ways:

"Human life is just like paper, which is used to record information, burned and recycled. Human culture also began with the discovery of paper. Paper and human beings are essentially related. It was amazing to experience universal human life through paper." (P6)

These physical but poetic engagements led the participants to actively interpret the artwork as related to their own bodily sensations and feelings:

"I felt warm. Unlike iron or concrete, the material is soft and warm. I felt the loneliness in general but I also felt that the director or author had a basic affection for the main character, so it's warm loneliness." (P1)

\section{The Application of Restriction of Control}

We found that restricting the audience's control within the CVR piece, such as by limiting interactions and navigation, provoked a sense of fragility, vulnerability and acceptance, which are feelings associated with loneliness and death. These uncontrollable situations and contexts made the participants more observant about the environment as well as feel vulnerability and other sensations. As we mentioned above, the participants were 'trapped' inside of the object or 'stuck' onto the object's surface and could not interact with the main character. However, in the end, the restriction forced them to leave the room and travel up into the sky.

Of the participants, 15 said they felt trapped or confined when they were inside of or stuck onto the objects, and it made them feel frustrated or helpless. However, when they had to leave home and go up to the sky, 8 participants said they were sad; 7 participants mentioned that they felt a release; and 6 participants described a mixture of feelings, such as happy-sad, bitter-sweet and melancholy-nostalgia:

"Claustrophobic at the beginning, you feel trapped. But you feel released, but free now. It is like a happy-sad. We all have to 
deal with death, and it will affect them somehow. You have no control but forced to think about those things." (P4)

"I feel helplessness and loneliness because nothing I can do. On the moment, I was trapped in a very solemn moment. ... When I go up to sky, I feel like I am actually going away. It is kind of sad. I think about the question of death." (P16)

The people who described sadness more than the other participants usually mentioned someone being left behind and separated after death. Those who mentioned the release described the act of letting go and escaping the pain and transcendental acceptance. These different responses also show that the way they appreciated the work is reflexive and that their own understanding and interpretation about life and death came from the sensation of vulnerability and uncontrollability:

“You can just watch it, can't do anything. As much as you want to interact or engage with something, you can't. It is the nice metaphor, being dead, a ghost.” (P21)

\section{The Creation of Various Disembodied Points of View}

We discovered that using various disembodied perspectives and different points of view provoked awareness about the participants' self-perceptions and forced them to engage in a multi-layered observation. The participants did not embody any specific virtual character, given the lack of a virtual body. Instead, they inhabited different objects in the piece, including the telephone, picture and TV. This meant that they were without a body, like a spirit or soul. It made them think about their identity and perceptions of themselves in a virtual situation and created different layers of connections and observations.

"There is no mirroring space; It goes back to the very fundamental awareness of a person's consciousness ... staying away from human-centric narrative. It forces you to be reflective, to question... what are you in this time and space, and what am I?” (P14)

"My perceptions are constantly expanding, but my identity is not exactly defined... I think the piece made me think about myself and beyond life, observing life." (P5)

Because their viewpoints kept changing, the audience also had varying intimacy and connection with the character. For example, participant 11 described the experience of changing perspectives as feeling like "pain switching" as she adopted the role of different entities in the widower's life:

"You start being a wife's portrait... I feel the embodiment of her pain, looking at her husband's suffering. But she switches the different objects, I feel that perspectives of pain kind of switches too. So, we knew here the daughter is calling him and not really making time for him, so it makes me wonder what he did in the past or if he properly communicates." (P11)

Four participants mentioned feeling more intimate with the main character when they were in the portrait or in the telephone but feeling more objective and observing when they were in the butterfly, TV and lamp. In general, due to the disembodied but unusual viewpoints, the participants started to question their identity and perception and create multi-layered connections with the character through different observations.

\section{DISCUSSION AND IMPLICATIONS}

The aim of this research was to explore the reflexive dimensions of VR storytelling. Our study of Anonymous suggests that four reflexive qualities enabled the audience to reflect on their individual experiences, fears and concerns about death and loneliness. Prior work in HCI has addressed these notions through the design of artefacts that help people to deal with end of life matters such as bereavement [30,39] and memorialization of the dead $[57,58]$. Our work is the first to look at the contribution CVR can make to the design of technology to stimulate reflection on death and loneliness. We suggest that VR could be a useful device for poetically delivering a sense of the dying, transcendence and grieving process due to VR's disembodied and immaterial media properties.

Anonymous used distancing effects to encourage reflexive and critical thinking about death. Based on our interviews, we found that the audience was influenced by four reflexive dimensions. These dimensions have implications for the design of future CVR pieces to provoke self and social reflection.

First, we found that the use of minimal and abstract aesthetics, such as a cardboard, hand-drawn virtual environment and a lack of explicit dialogue, allowed people to project their own feelings and thoughts onto the piece with some emotional distance. We believe this dimension also allowed people to project their feelings without being distracted by visual details. In CVR, the audience is surrounded by $360^{\circ}$ images and sounds. This amount of audiovisual information has the potential to cause distraction, and if all the information is designed with a high degree of detail, the audience may focus on trivial things not particularly related to the theme or story. Furthermore, it might be difficult for them to reflect upon their own feelings and thoughts if they are too immersed into the specific details of the virtual environment. Thus, we suggest that the general idea of using abstract aesthetics can be applied in other CVR pieces to enhance the audience's engagement with key characteristics that speak to the underlying themes of the story, creating interpretive gaps that encourage people to sensemake using their own life experiences.

Second, the use of everyday materials and textures in Anonymous made familiar objects and physical sensations seem strange. In everyday life, we physically and intuitively understand the textures and materials we encounter. If we are in a VR setting surrounded by everyday textures, we cannot touch these textures, but we feel and know them. This creates a feeling of estrangement as people fill in the gap between what they feel, what they see, and what they physically experience. The general dimension of making the familiar seem strange could be used by the CVR designer to provoke certain bodily sensations, in line with the aims of the piece.

Third, we found that the restriction of control through noninteractability and non-navigability of the environment elicited a sense of vulnerability, fragility and acceptance. VR has been surrounded by simple ideal perceptions such as that VR is somehow 'better' than traditional media because it can engage people physically and encourage them to participate in situations or a story [48]. However, the sense of limitation is also part of bodily engagement, and we can also participate in the 
virtual environment unethically without awareness. Therefore, active and passive participation based on level of control are too simplistic of a division. In fact, participation is under the control of the designer and is something that can be varied depending on the goals of the piece. Anonymous demonstrates how restricting control and immersion in VR can be an effective tool for simulating those sensations, especially when making people reflect about issues related to social isolation, disconnection, alienation and death.

The last reflexive element we found is the various disembodied points of view, which elicited the participants' awareness of their self-perception and prompted multi-layered observation. Disembodiment is not only the disconnection from our physical body but also the catalyst for re-embodiment, which is the reconstruction of our physical sensations [45,62]. For example, we never inhabit objects in real life. Those disembodied experiences in Anonymous generated new kinds of sensations, and they made people reflect upon their everyday self-perception. In a movie or a game, various points of views are used, but the audience is still positioned as spectators separated from the screen. However, in VR, the audience physically embodies the camera's perception. Without physical bodies, users can have a bodily experience from multiple perspectives. In these situations, they cognitively fill in the gaps between the new kinds of embodied virtual perception and bodily sensations in the physical world.

One of the design intentions of Anonymous was to stimulate reflection about death and loneliness, both at the individual and societal levels. The main theme of Anonymous is the broader societal issue of the "no-relationship society", which is an increasing problem that is contributing to loneliness and solitary death around the globe [11]. Our piece drew on Brechtian distancing effects, which were developed in many art forms to break simple immersion while eliciting reflexive and critical thinking on societal issues. However, we found that people tended to reflect on their own individual issues and experiences after viewing Anonymous, rather than the broader societal problem. The piece contained some poetic cues around social issues, such as the widower's job history and political events, but these were not strong enough to cause participants to talk directly about the "no-relationship society". This may be due to a limited awareness of the bigger problem. Future pieces that aim to provoke reflection on societal problems could explore the use of more informative and directly related social cues, or include more prominent elements in the story to inform the audience about the wider topic at hand.

In summary, the abstract, minimal and everyday texture aesthetics can be considered a production of an audiovisual design that has implications for the reflexive dimensions of CVR. The restriction of control can be more related to technical decision-making based on immersion and interactivity that we mentioned above. The various disembodied viewpoints can be the factors of cinematic considerations, such as the camera position and angles. All four factors were exploited based on the method of using the technical limitations of VR technologies, such as the limits of realistic representations, restrictions of immersion and interactivity, and partial disem- bodiment. Overall, this research suggests that CVR has the potential to be an effective tool for simulating life experiences by providing new kinds of embodied reflections that force the audience's thoughts and feelings to surface while maintaining ongoing bodily awareness $[6,26,37]$.

\section{Limitations and Future Work}

This research presents an early but valuable contribution in the emerging space of VR storytelling. Although our work provides important insights into the audience experience and reflexive capabilities of CVR, it is important to note that we have only studied one artistic piece. Future work may wish to analyze other VR experiences to further elaborate the grammar of VR storytelling. The artistic works mentioned earlier in this paper, including After Solitary, Remain at Home and $6 x 9$, do not appear to have been studied in terms of the audience's reaction. These pieces could be compared and contrasted with our findings in order to further understand the reflexive dimensions of CVR. In future work, we intend to create new CVR pieces, based on various technical constraints and potentials to explore different social problems.

Although our participants demonstrated considerable engagement with Anonymous, an issue that may hamper the analysis of audience experience is their initial unfamiliarity with VR technology. Ten of our 23 participants had never used VR before, and while only one person seemed mildly distracted by the technology, the novelty of the experience may have impacted the degree of interest and engagement they exhibited. Future work should keep this in mind when studying CVR.

\section{CONCLUSION}

This paper presented a reflexive storytelling design for CVR. For practical exploration, we created an interactive CVR piece called Anonymous to facilitate self-reflection about death and loneliness. We investigated three different elements - immersion, interactivity, and narrative - for the storytelling design. Based on Brechtian theory, we exploited the technical limitation of VR technologies as distancing effects for the reflexive dimension. We conducted in-depth interviews to understand the audience's experiences. The interviews revealed that four design elements - abstract and minimal aesthetics, everyday materials and textures, the restriction of control, and multiple disembodied points of view - supported deep and personalised reflection on death and loneliness. Based on these findings, we illustrated CVR's potential storytelling design for promoting embodied self-reflection about social issues related to isolation, alienation and human mortality.

\section{ACKNOWLEDGEMENTS}

This project was supported by SensiLab at Monash University and the artist collective Artengine. We gratefully acknowledge the creative skills and support of our team and colleagues. We also thank Vince Dziekan, Toby Gifford, Mike Yeates, Aiden Hatcher, Eunsung Jeon, Rimi Choi, Nina Rajcic, Jarrod Knibbe, Tom Bartindale, Oscar Raby and Eugenia Kim for helping us to develop our research ideas and processes. We also express gratitude to all of our interview participants and the widower who inspired us to form the story of Anonymous. 


\section{REFERENCES}

[1] Anne Allison. 2015. Discounted life: social time in relationless Japan. boundary 2 42, 3 (2015), 129-141.

[2] Aristoteles and James Hutton. 1982. Aristotle's Poetics. WW Norton New York.

[3] Sojung Bahng. 2018. Cinematic VR as a Reflexive Tool for Critical Empathy. In International Conference on Interactive Digital Storytelling. Springer, 363-366.

[4] Sojung Bahng, Toby Gifford, and Jon McCormack. 2019. Anonymous: VR Storytelling Through Alienation and Reflexivity. In Proceedings of the 25th International Symposium on Electronic Art. ISEA International, 120-127.

[5] Chris Bevan, David Philip Green, Harry Farmer, Mandy Rose, Kirsten Cater, Danaë Stanton Fraser, and Helen Brown. 2019. Behind the Curtain of the 'Ultimate Empathy Machine': On the Composition of Virtual Reality Nonfiction Experiences. In Proceedings of the 2019 CHI Conference on Human Factors in Computing Systems (CHI '19). ACM, New York, NY, USA, Article 506, 12 pages. DOI :

http://dx.doi .org/10.1145/3290605.3300736

[6] Daniel Black. 2018. Digital Interfacing: Action and Perception Through Technology. Routledge.

[7] Ernst Bloch, Anne Halley, and Darko Suvin. 1970. "Entfremdung, Verfremdung": Alienation, Estrangement. The Drama Review: TDR (1970), 120-125.

[8] Virginia Braun and Victoria Clarke. 2006. Using thematic analysis in psychology. Qualitative research in psychology 3, 2 (2006), 77-101.

[9] Bertolt Brecht. 2014. Brecht on theatre. Bloomsbury Publishing.

[10] John Bucher. 2017. Storytelling for virtual reality: methods and principles for crafting immersive narratives. Routledge.

[11] John T. Cacioppo and Stephanie Cacioppo. 2018. The growing problem of loneliness. The Lancet 391, 10119 (2018), 426.

[12] Metin Çavuş and Oğuzhan Özcan. 2010. To watch from distance: an interactive film model based on Brechtian film theory. Digital Creativity 21, 2 (2010), 127-140.

[13] Daniel Joseph Dunne. 2014. Brechtian Alienation in Videogames. Press Start 1, 1 (2014), 79-99.

[14] Terry Eagleton. 1985. Brecht and rhetoric. New Literary History 16, 3 (1985), 633-638.

[15] Eivind Flobak, Jo D. Wake, Joakim Vindenes, Smiti Kahlon, Tine Nordgreen, and Frode Guribye. 2019. Participatory Design of VR Scenarios for Exposure Therapy. In Proceedings of the 2019 CHI Conference on Human Factors in Computing Systems (CHI '19). Association for Computing Machinery, New York, NY, USA, Article Paper 569, 12 pages. DOI :

http://dx.doi.org/10.1145/3290605.3300799
[16] Gonzalo Frasca. 2001. Videogames of the oppressed: Videogames as a means for critical thinking and debate. Master's thesis. School of Literature, Communication and Culture, Georgia Institute of Technology.

[17] Yasuyuki Fukukawa. 2011. Solitary death: a new problem of an aging society in Japan. Journal of the American Geriatrics Society 59, 1 (2011), 174-175.

[18] Alessandra Gorini, Claret S Capideville, Gianluca De Leo, Fabrizia Mantovani, and Giuseppe Riva. 2011. The role of immersion and narrative in mediated presence: the virtual hospital experience. Cyberpsychology, Behavior, and Social Networking 14, 3 (2011), 99-105.

[19] Connor Graham. 2015. The photograph reaches out: uses of photographs of the dead in China. Mortality 20, 4 (2015), 351-374.

[20] Lars Hallnäs and Johan Redström. 2001. Slow technology-designing for reflection. Personal and ubiquitous computing 5, 3 (2001), 201-212.

[21] Ben Herson. 2016. Empathy Engines: How Virtual Reality Films May (or May Not) Revolutionize Education. Comparative Education Review 60, 4 (2016), 853-862.

[22] Soong-Nang Jang, Sung-Il Cho, Jiyeun Chang, Kachung Boo, Hyun-Goo Shin, Hyejung Lee, and Lisa F Berkman. 2009. Employment status and depressive symptoms in Koreans: results from a baseline survey of the Korean Longitudinal Study of Aging. Journals of Gerontology Series B: Psychological Sciences and Social Sciences 64, 5 (2009), 677-683.

[23] Seokho Kim and Jaeun Lim. 2017. Patterns of Social Support Networks in Japan and Korea. The Senshu social well-being review 4 (2017), 3-19.

[24] Eric Klinenberg. 2013. Going solo: the extraordinary rise and surprising appeal of living alone. Penguin.

[25] Jarrod Knibbe, Jonas Schjerlund, Mathias Petraeus, and Kasper Hornbæk. 2018. The Dream is Collapsing: The Experience of Exiting VR. In Proceedings of the 2018 CHI Conference on Human Factors in Computing Systems (CHI '18). ACM, New York, NY, USA, Article 483, 13 pages. DOI : http://dx.doi.org/10.1145/3173574.3174057

[26] Jarrod Mark Knibbe. 2015. Designing for embodied reflection. Ph.D. Dissertation. University of Bristol.

[27] Brenda Laurel. 1993. Computers as Theater. EUA. (1993).

[28] Raquel Ritter Longhi. 2017. Immersive narratives in web journalism. Between interfaces and virtual reality. Estudos em Comunicação 1, 25 (2017).

[29] Lev Manovich. 2001. The language of new media. MIT press. 
[30] Michael Massimi and Ronald M. Baecker. 2011. Dealing with Death in Design: Developing Systems for the Bereaved. In Proceedings of the SIGCHI Conference on Human Factors in Computing Systems (CHI'11). Association for Computing Machinery, New York, NY, USA, 1001-1010. DOI :

http://dx.doi.org/10.1145/1978942.1979092

[31] Michael Massimi and Andrea Charise. 2009. Dying, Death, and Mortality: Towards Thanatosensitivity in HCI. In CHI '09 Extended Abstracts on Human Factors in Computing Systems (CHI EA '09). Association for Computing Machinery, New York, NY, USA, 2459-2468. DOI :

http://dx.doi.org/10.1145/1520340.1520349

[32] Michael Massimi, William Odom, Richard Banks, and David Kirk. 2011. Matters of Life and Death: Locating the End of Life in Lifespan-Oriented Hci Research. In Proceedings of the SIGCHI Conference on Human Factors in Computing Systems (CHI'11). Association for Computing Machinery, New York, NY, USA, 987-996. DOI:

http://dx.doi .org/10.1145/1978942.1979090

[33] John Mateer. 2017. Directing for Cinematic Virtual Reality: how the traditional film director's craft applies to immersive environments and notions of presence. Journal of Media Practice 18, 1 (2017), 14-25.

[34] Dan P McAdams. 1993. The stories we live by: Personal myths and the making of the self. Guilford Press.

[35] Jamie McRoberts. 2018. Are we there yet? Media content and sense of presence in non-fiction virtual reality. Studies in Documentary Film 12, 2 (2018), 101-118.

[36] Joshua McVeigh-Schultz, Anya Kolesnichenko, and Katherine Isbister. 2019. Shaping Pro-Social Interaction in VR: An Emerging Design Framework. In Proceedings of the 2019 CHI Conference on Human Factors in Computing Systems (CHI '19). Association for Computing Machinery, New York, NY, USA, Article Paper 564, 12 pages. DOI :

http://dx.doi .org/10.1145/3290605.3300794

[37] Maurice Merleau-Ponty. 2013. Phenomenology of perception. Routledge.

[38] Chris Milk. 2015. How virtual reality can create the ultimate empathy machine. Online (Accessed 22.10.2019). (2015).

[39] Wendy Moncur, Miriam Julius, Elise Van Den Hoven, and David Kirk. Story Shell: the participatory design of a bespoke digital memorial. In Proceedings of the 4th Participatory Innovation Conference. 470-477.

[40] Paul Moody. 2017. An 'amuse-bouche at best': 360 VR storytelling in full perspective. International Journal of E-Politics (IJEP) 8, 3 (2017), 42-50.

[41] Sheryl Mousley and Shari Frilot. 2016. New Frontier at Sundance Film Festival: 10 Years of Changing Boundaries. Leonardo 49, 2 (2016), 109-112.
[42] Hye Yeon Nam, Zachary Berkowitz, and Edgar Berdahl. 2017. Invisible: A Critical Digital Artwork as Performance. In Proceedings of the 2017 CHI Conference Extended Abstracts on Human Factors in Computing Systems (CHI EA '17). Association for Computing Machinery, New York, NY, USA, 1399-1404. DOI :

http://dx.doi.org/10.1145/3027063.3052547

[43] William Odom, Richard Banks, Abigail Durrant, David Kirk, and James Pierce. 2012. Slow Technology: Critical Reflection and Future Directions. In Proceedings of the Designing Interactive Systems Conference (DIS '12). ACM, New York, NY, USA, 816-817. DOI : http://dx.doi.org/10.1145/2317956.2318088

[44] Dana B Polan. 1974. Brecht and the politics of self-reflexive cinema. Jump Cut 1 (1974).

[45] Spiros Polimeris and Christine Calfoglou. 2014. Art journeying in times of globalization: The voice of disembodiment. International Journal of Cultural and Digital Tourism 1, 2 (2014).

[46] Jay Ruby. 1977. The image mirrored: Reflexivity and the documentary film. Journal of the University Film Association 29, 4 (1977), 3-11.

[47] Marie-Laure Ryan. 1999. Immersion vs. interactivity: Virtual reality and literary theory. SubStance 28, 2 (1999), 110-137.

[48] Marie-Laure Ryan. 2015. Narrative as virtual reality 2: Revisiting immersion and interactivity in literature and electronic media. Vol. 2. JHU Press.

[49] Donald A Schön. 2017. The reflective practitioner: How professionals think in action. Routledge.

[50] Phoebe Sengers, Kirsten Boehner, Shay David, and Joseph "Jofish" Kaye. 2005. Reflective Design. In Proceedings of the 4th Decennial Conference on Critical Computing: Between Sense and Sensibility (CC'05). Association for Computing Machinery, New York, NY, USA, 49-58. DOI :

http://dx.doi.org/10.1145/1094562 . 1094569

[51] Aparna Shankar, Anne McMunn, James Banks, and Andrew Steptoe. 2011. Loneliness, social isolation, and behavioral and biological health indicators in older adults. Health Psychology 30, 4 (2011), 377.

[52] Donghee Shin. 2018. Empathy and embodied experience in virtual environment: To what extent can virtual reality stimulate empathy and embodied experience? Computers in Human Behavior 78 (2018), 64-73.

[53] Mel Slater and Sylvia Wilbur. 1997. A framework for immersive virtual environments (FIVE): Speculations on the role of presence in virtual environments. Presence: Teleoperators \& Virtual Environments 6, 6 (1997), 603-616. 
[54] Maggie Burnette Stogner. 2011. Communicating Culture in the 21st Century: The Power of Media-Enhanced Immersive Storytelling. Journal of Museum Education 36, 2 (2011), 189-198.

[55] Matthew Taylor. 2012. Not with a bang but a whimper: Muen shakai and its implications. Anthropoetics 18, 1 (2012).

[56] Jan Uhde. 1974. The Influence of Bertolt Brecht's Theory of Distanciation on the Contemporary Cinema, Particularly on Jean-Luc Godard. Journal of the University Film Association (1974), 28-44.

[57] Daisuke Uriu and William Odom. 2016. Designing for Domestic Memorialization and Remembrance: A Field Study of Fenestra in Japan. In Proceedings of the 2016 CHI Conference on Human Factors in Computing Systems (CHI'16). Association for Computing Machinery, New York, NY, USA, 5945-5957. DOI : http://dx.doi.org/10.1145/2858036.2858069

[58] Daisuke Uriu and Naohito Okude. 2010. ThanatoFenestra: Photographic Family Altar Supporting a Ritual to Pray for the Deceased. In Proceedings of the 8th ACM Conference on Designing Interactive Systems
(DIS '10). Association for Computing Machinery, New York, NY, USA, 422-425. DOI :

http://dx.doi.org/10.1145/1858171.1858253

[59] Mirjam Vosmeer and Ben Schouten. 2014. Interactive cinema: engagement and interaction. In International Conference on Interactive Digital Storytelling. Springer, 140-147.

[60] Danielle Wilde, Anna Vallgårda, and Oscar Tomico. 2017. Embodied Design Ideation Methods: Analysing the Power of Estrangement. In Proceedings of the 2017 CHI Conference on Human Factors in Computing Systems (CHI'17). Association for Computing Machinery, New York, NY, USA, 5158-5170. DOI : http://dx.doi.org/10.1145/3025453.3025873

[61] Virpi Ylänne. 2015. Representations of ageing in the media. Routledge handbook of cultural gerontology (2015), 369-375.

[62] Âli Yurtsever and Umut Burcu Tasa. 2009. Redefining the body in cyberculture: Art's contribution to a new understanding of embodiment. The Real and the Virtual (2009), 1-12. 